\title{
Caracterização e incorporação de cinza de resíduo sólido urbano em cerâmica vermelha
}

\section{(Characterization and incorporation of MSWI ash in red ceramic)}

\author{
N. C. Coutinho, C. M. F. Vieira \\ Laboratório de Materiais Avançados, Universidade Estadual do Norte Fluminense Darcy Ribeiro, Av. Alberto \\ Lamego, 2000, Campos dos Goytacazes, RJ 28013-602 \\ nicollepetro@gmail.com,vieira@uenf.br
}

\begin{abstract}
Resumo
Este trabalho tem por objetivo avaliar o efeito da incorporação de cinza de resíduo sólido urbano nas propriedades físicas e mecânicas da cerâmica vermelha. Foram preparados corpos de prova por prensagem uniaxial a $20 \mathrm{MPa}$ para queima a $750{ }^{\circ} \mathrm{C}$, com incorporações de resíduo ( $70 \%$ de cinza de fundo e $30 \%$ de cinza volante) de até $20 \%$ em massa em argila caulinítica da região de Campos dos Goytacazes, RJ. As matérias-primas foram submetidas à análise química, mineralógica, física e morfológica. As propriedades físicas e mecânicas avaliadas nos corpos de prova foram: absorção de água, retração linear e tensão de ruptura à flexão. Os resultados sugerem a incorporação de quantidades em torno de $5 \%$ em massa de cinzas na argila para não prejudicar o comportamento mecânico da cerâmica, bem como evitar o aparecimento de porosidade aberta excessiva, podendo ser esta uma destinação final ambientalmente adequada para as cinzas de resíduo sólido urbano.

Palavras-chave: cerâmica vermelha, cinzas, incorporação, propriedades, resíduos.
\end{abstract}

\begin{abstract}
This study aims to evaluate the effect of the incorporation of municipal solid waste incineration (MSWI) ash in the physical and mechanical properties of red ceramic. Specimens were prepared by uniaxial mold-press at $20 \mathrm{MPa}$ followed by firing at $750{ }^{\circ} \mathrm{C}$, with residue incorporation (70 wt\% of bottom ash and $30 \mathrm{wt} \%$ of fly ash) of up to $20 \mathrm{wt} \%$ in kaolinitic clay of Campos dos Goytacazes, RJ. Raw materials were subjected to chemical, mineralogical, physical and morphological analysis. The physical and mechanical properties evaluated were: water absorption, linear shrinkage, and flexural rupture strength. The results suggest the incorporation of amounts around $5 \mathrm{wt} \%$ of ash in clay to avoid damaging the mechanical behavior of ceramic and avoid the appearance of excessive porosity, and this may be a final destination environmentally suitable for the MSWI ashes.
\end{abstract}

Keywords: red ceramic, ash, incorporation, properties, waste.

\section{INTRODUÇÃO}

Os processos industriais originam resíduos que são próprios de suas atividades [1], no entanto, as indústrias têm buscado alternativas para a disposição dos resíduos sólidos gerados, devido às exigências dos órgãos ambientais ou pelo fato de adquirirem aumento da credibilidade ante o mercado consumidor. Neste sentido, muitos países têm adotado, além da técnica da reciclagem, a incineração, que reduz expressivamente o volume de resíduo sólido a ser disposto nos aterros sanitários e o seu poder calorífico gera energia elétrica durante a combustão, tornando-se uma prática interessante do ponto de vista ambiental [2]. Apesar de a incineração ser considerada como uma forma de disposição final, este processo não deveria se apresentar como uma solução completa e definitiva, visto que durante a queima dos resíduos são geradas cinza de fundo e cinza volante, que necessitam de outra forma de disposição. Além disso, por estarem normalmente contaminadas por metais pesados, requerem processos de estabilização e solidificação antes de sua disposição direta nos aterros [3].
A incineração é um processo de oxidação em temperaturas altas, com a queima dos gases entre 1000 e $1450{ }^{\circ} \mathrm{C}$, necessitando ocorrer em instalações bem projetadas e corretamente operadas, onde há a transformação de materiais e a destruição dos microrganismos presentes nos resíduos sólidos, buscando, essencialmente, reduzir seu volume e sua massa [4]. A Usinaverde S/A é uma empresa de capital privado situada na cidade universitária da UFRJ - Ilha do Fundão no Rio de Janeiro. Implantada em 2004, a empresa apresenta soluções ambientais para a destinação final dos resíduos sólidos urbanos (RSU) através do processo de incineração com geração de energia. A capacidade nominal da unidade é de 30 toneladas por dia de RSU de aterro sanitário, já triado previamente na Companhia Municipal de Limpeza Urbana do Rio de Janeiro para segregação de recicláveis. Com o processo de incineração, a $850{ }^{\circ} \mathrm{C}$, são obtidos de 8 a $10 \%$ em volume das duas cinzas, que representam cerca de $80 \%$ de cinza de fundo e $20 \%$ de cinza volante. De acordo com a Usinaverde S/A, 10 a $15 \%$ em massa do lixo transformam-se em cinzas [5].

A prática da reciclagem através da utilização de resíduos 
industriais na fabricação de materiais da construção civil pode trazer inúmeros benefícios ambientais por substituir a utilização de recursos naturais por resíduos recicláveis [1]. O objetivo deste trabalho é avaliar o efeito da incorporação de cinza de resíduo sólido urbano nas propriedades físicas e mecânicas da cerâmica vermelha.

\section{MATERIAIS E MÉTODOS}

Os materiais utilizados foram os seguintes: massa de cerâmica argilosa caulinítica do município de Campos dos Goytacazes, RJ, e cinza de resíduo sólido urbano proveniente da unidade de incineração da Usinaverde S/A, da cidade do Rio de Janeiro (30\% de cinzas volantes e 70\% de cinzas de fundo). As cinzas provêm da queima de matéria orgânica e plástico do tipo polietileno. É possível encontrar ainda pequenas quantidades de papel, tecido, madeira, couro e PVC. As matérias-primas foram caracterizadas por meio de fluorescência de raios X (FRX), difração de raios X (DRX), peneiramento e sedimentação, microscopia óptica (MO) e microscopia eletrônica de varredura (MEV). Por FRX foi determinada a composição química das matérias-primas, em espectrômetro PW 2400, Phillips. A composição mineralógica qualitativa das matérias-primas foi obtida através de DRX em amostras em forma de pó, em difratômetro XRD 7000, Shimadzu, operando com radiação de cobre $(\mathrm{Cu}-\mathrm{K} \alpha)$ e varredura $2 \theta$ variando entre $5^{\circ}$ e $60^{\circ}$. As interpretações qualitativas dos difratogramas foram efetuadas por comparação com padrões contidos no banco de dados PDF-2 em software Bruker DiffracPlus. A distribuição de tamanho de partículas das matérias-primas foi determinada pela combinação das técnicas de peneiramento e sedimentação de acordo com a norma NBR 7181 (1984). A MO foi realizada em microscópio MoticAgar Scientific e a MEV realizada em microscópio SSX 550, Shimadzu. As formulações foram homogeneizadas em moinho de bolas durante $30 \mathrm{~min}$, peneiradas em 20 mesh $(0,841 \mathrm{~mm})$ e secas em estufa a $110^{\circ} \mathrm{C}$ até massa constante.

Foram preparados corpos de prova com incorporações de $0,5,10$ e $20 \%$ em massa de resíduo $(70 \%$ de cinza de fundo e $30 \%$ de cinza volante), por prensagem uniaxial a 20 $\mathrm{MPa}$, nas dimensões $114,0 \mathrm{~mm} \times 25,0 \mathrm{~mm} \times 11,0 \mathrm{~mm}$. As composições foram homogeneizadas a seco e umedecidas a $8 \%$ em massa. A queima dos corpos de prova foi feita em forno tipo mufla com microprocessador a $750{ }^{\circ} \mathrm{C}$, com taxa de aquecimento de $3{ }^{\circ} \mathrm{C} / \mathrm{min}$ e isoterma de 60 $\min$ na temperatura de patamar. $\mathrm{O}$ resfriamento foi feito por convecção natural, desligando-se o forno. Os corpos cerâmicos queimados foram submetidos a ensaios físicos e mecânicos para determinação de absorção de água, retração linear e tensão de ruptura à flexão em três pontos, e ainda a DRX e MO através dos mesmos equipamentos descritos anteriormente.

\section{RESULTADOS E DISCUSSÃO}

A Tabela I apresenta a composição química das matérias-primas. É possível observar que a massa cerâmica é predominantemente constituída de $\mathrm{SiO}_{2}$ e $\mathrm{Al}_{2} \mathrm{O}_{3}$, que estão em sua maior parte combinados, formando os aluminossilicatos como a mica muscovita e a caulinita. A cor é uma propriedade importante dos produtos de argila. Vários fatores determinam esta cor, mas o ferro é geralmente seu principal determinante. A cor de um produto de argila é influenciada pelo estado de oxidação do ferro, o tamanho das partículas de minerais de ferro, tais como hematita e goetita, a temperatura de queima e o grau de vitrificação, a proporção de alumina, cal e magnésio na cerâmica e a composição dos gases que entram em contato com o material durante a queima [6]. As cerâmicas que ficam brancas após a queima contêm menos de $1 \%$ de $\mathrm{Fe}_{2} \mathrm{O}_{3}$. Cerâmicas que contêm entre $1 \%$ e $5 \%$ de $\mathrm{Fe}_{2} \mathrm{O}_{3}$ apresentam coloração rosácea, e cerâmicas vermelhas contêm $5 \%$ ou mais de $\mathrm{Fe}_{2} \mathrm{O}_{3}$ em sua composição. $\mathrm{O}$ teor relativamente baixo de $\mathrm{Fe}_{2} \mathrm{O}_{3}$, menor que $3 \%$, conferiu uma coloração bege-rosácea ao produto após a queima. $\mathrm{O} \mathrm{K}_{2} \mathrm{O}$ é um óxido fundente que contribui na formação de fase líquida. $O$ percentual observado de $1,21 \%$ é típico de argilas cauliníticas e considerado baixo em comparação com argilas ilíticas, também conhecidas como argilas fundentes. A perda ao fogo (PF) ocorre principalmente devido à perda de água de constituição da caulinita. Excessiva perda ao fogo ocasiona porosidade e retração durante a queima. A desidratação de hidróxidos e oxidação de matéria orgânica também contribuem para a perda ao fogo das argilas de Campos dos Goytacazes, RJ [7].

A análise química das cinzas foi realizada com o resíduo como recolhido na usina fornecedora, não sofrendo processo de lavagem. Os principais componentes presentes nas cinzas são o óxido de cálcio $(\mathrm{CaO})$, óxido de silício $\left(\mathrm{SiO}_{2}\right)$ e alumina $\left(\mathrm{Al}_{2} \mathrm{O}_{3}\right)$, tal como reportado na literatura, porém em percentuais diferentes dos encontrados por outros autores [8-12]. Essa diferença na composição química das cinzas pode estar associada às diferentes composições do resíduo sólido que as originou, bem como ao processo de queima

Tabela I - Composição química das matérias-primas ( $\%$ em massa).

[Table I - Chemical composition of raw materials (wt\%).]

\begin{tabular}{cccccccccc}
\hline Matéria-prima & $\mathrm{SiO}_{2}$ & $\mathrm{Al}_{2} \mathrm{O}_{3}$ & $\mathrm{CaO}$ & $\mathrm{Fe}_{2} \mathrm{O}_{3}$ & $\mathrm{MgO}$ & $\mathrm{TiO}_{2}$ & $\mathrm{~K}_{2} \mathrm{O}$ & $\mathrm{Na}_{2} \mathrm{O}$ & $\mathrm{PF}$ \\
\hline Massa argilosa & 62,98 & 21,23 & 0,35 & 2,73 & 0,48 & 0,89 & 1,21 & 0,38 & 9,47 \\
Cinza leve & 12,2 & 8,4 & 28,25 & 2,7 & 2,1 & 1,9 & 1,8 & 2,1 & 11,4 \\
Cinza de fundo & 19,3 & 13,1 & 26,5 & 3,7 & 3,3 & 1,8 & 1,2 & 2,3 & 19,5 \\
\hline
\end{tabular}



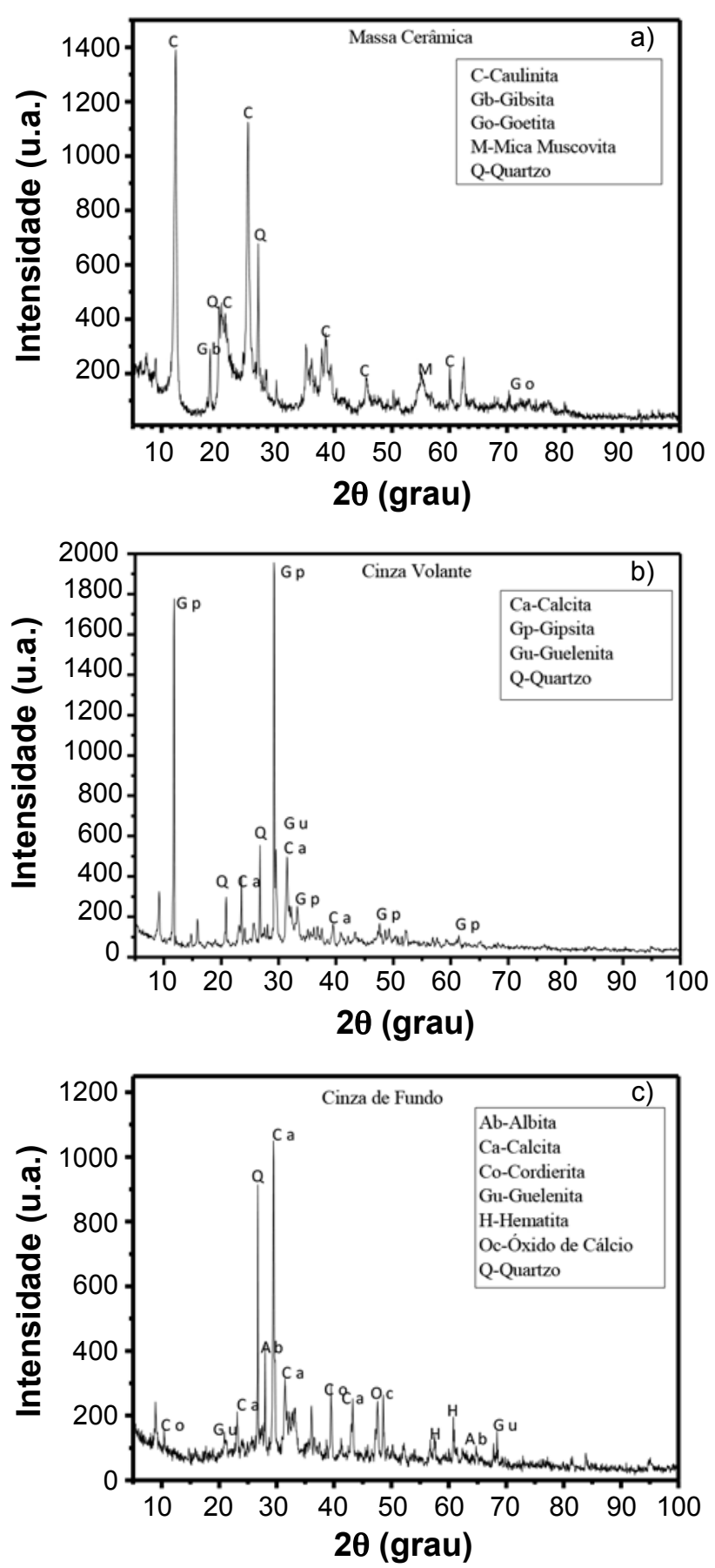

Figura 1: Difratogramas de raios $X$ da massa cerâmica (a), cinza de fundo (b) e cinza volante (c).

[Figure 1: X-ray diffraction patterns of the clayey mass (a), bottom ash (b), and fly ash (c).]

do resíduo. A perda ao fogo das cinzas está associada à decomposição de carbonatos e eliminação de água de hidróxidos, conforme constituição mineralógica apresentada nas Figs. 2 e 3. A combustão incompleta de constituintes do lixo, como, por exemplo, matéria orgânica, papel, plástico e madeira, também contribui para a perda ao fogo. A cinza de fundo, pesada, tem uma PF maior que a cinza leve devido à presença remanescente dos constituintes presentes no lixo, descritos anteriormente.

As Figs. 1a, 1b e 1c apresentam os difratogramas de raios $\mathrm{X}$ da massa cerâmica, da cinza volante e da cinza de fundo, respectivamente. Nota-se na Fig. 1a que os picos de difração predominantes são correspondentes à caulinita e ao quartzo. Outros minerais identificados são gibsita, goetita e mica muscovita. A caulinita é o argilomineral presente em muitas argilas usadas para fabricação de materiais da construção civil, sendo responsável pela plasticidade da argila [7]. O quartzo é considerado como a principal impureza presente nas argilas e atua como matéria-prima não plástica e inerte durante a queima. A gibsita fornece aumento da refratariedade das argilas e perda de massa durante a queima. A goetita representa o teor de ferro presente na massa argilosa. A mica muscovita é um mineral que apresenta morfologia lamelar, podendo causar defeitos na cerâmica. Devido à presença de óxidos alcalinos, a mica pode atuar como fundente quando em tamanho reduzido, sendo responsável por promover fase líquida nas peças sinterizadas [7]. Na Fig. 1b, observase que as fases cristalinas presentes na cinza volante são quartzo, guelenita, gipsita e calcita. A presença dessas fases deve-se à composição diversificada do RSU do qual originaram-se as cinzas estudadas. E na Fig. 1c, as fases cristalinas predominantes na cinza de fundo são albita, calcita, cordierita, guelenita, hematita, óxido de cálcio e quartzo.

A Fig. 2 mostra a distribuição de tamanho de partículas das matérias-primas utilizadas para confecção das peças. $\mathrm{Na}$ massa cerâmica, a fração argila é de $45,1 \%$, fração silte de $20,3 \%$ e fração areia de $34,6 \%$. A fração argila está associada com tamanho de partícula inferior a $2 \mu \mathrm{m}$ e confere à massa cerâmica plasticidade em mistura com água, possibilitando assim alcançar uma consistência plástica que possibilita conformar as peças por extrusão. A fração silte compreende partículas com tamanho esférico equivalente entre 2 e $20 \mu \mathrm{m}$, e a fração areia partículas maiores que 20 $\mu \mathrm{m}$. Sendo assim, a massa cerâmica estudada comporta-se como plástica. As cinzas volantes apresentaram fração fina (tamanho de partícula inferior a $2 \mu \mathrm{m}$ ) de $3,1 \%$, fração média (tamanho de partícula entre 2 e $20 \mu \mathrm{m}$ ) de $54,9 \%$ e fração grosseira (tamanho de partícula maior que $20 \mu \mathrm{m}$ ) de $42 \%$. $\mathrm{E}$ as cinzas de fundo apresentaram fração fina de $1,4 \% \mathrm{em}$ massa, fração média de $11,2 \%$ em massa e fração grosseira de $87,3 \%$. Dessa forma, as cinzas de fundo funcionam como desplastificante. A partículas das duas cinzas estudadas apresentam-se quase que totalmente maiores que $2 \mu \mathrm{m}$, o que as confere um comportamento não plástico. Os teores de materiais plásticos e não plásticos são diretamente relacionados com a trabalhabilidade/plasticidade da massa cerâmica, influenciando nos fatores tecnológicos como conformação, retração de secagem, resistência mecânica e no comportamento de queima das peças.

As Figs. 3a, 3b e 3c apresentam as micrografias obtidas por microscopia eletrônica de varredura da massa cerâmica, cinza volante e cinza de fundo, respectivamente. A massa cerâmica apresenta partículas de tamanhos variados e diferentes morfologias. Observa-se que tanto a cinza volante, 


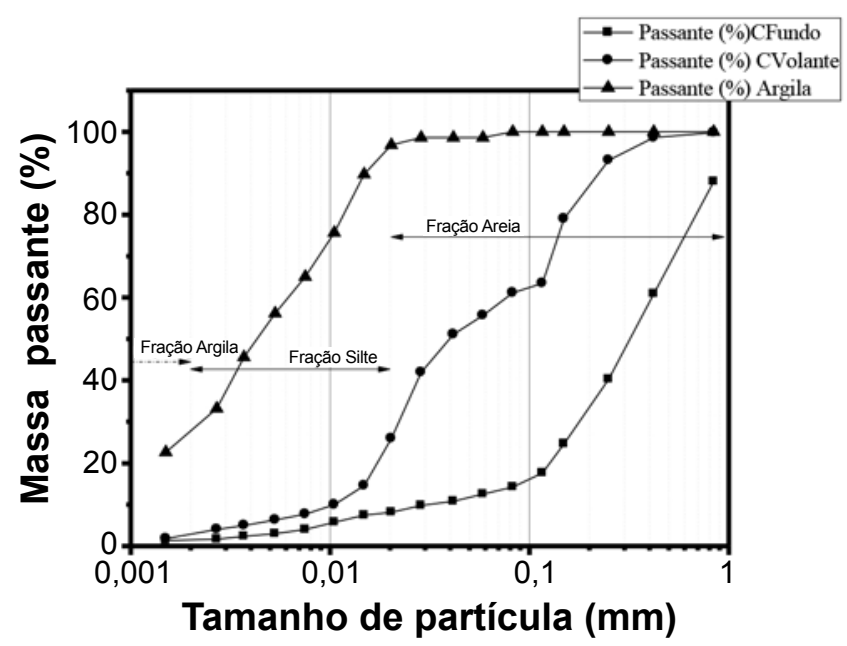

Figura 2: Distribuição de tamanho de partículas das matériasprimas.

[Figure 2: Distribution of particle size of raw materials.]

quanto a cinza de fundo são formadas por aglomerados com formas, respectivamente, cilíndrica e arredondada, resultante da aglomeração de partículas. As cinzas apresentam um produto sinterizado poroso em sua estrutura e não partículas espaçadas entre si.

A Fig. 4a mostra a absorção de água das peças cerâmicas queimadas a $750{ }^{\circ} \mathrm{C}$. Observa-se que a incorporação de $5 \%$ de cinza reduziu a absorção de água da massa cerâmica em $10,8 \%$, de $20,8 \%$ para $18,62 \%$. Entretanto, quantidades maiores de cinzas tendem a aumentar levemente a absorção de água, embora com valores ainda menores que a massa cerâmica pura. Este comportamento indica que a cinza deve ter alterado o empacotamento da argila na etapa de conformação, contribuindo assim para a redução da porosidade. Nota-se ainda que todas as formulações atendem o valor especificado por norma para blocos de vedação, ou seja, máximo de $22 \%$ de absorção de água [13]. Para telhas, a absorção máxima é de $20 \%$ [14] e todas as composições com cinzas atenderam a especificação. A Fig. $4 \mathrm{~b}$ apresenta a retração linear das peças cerâmicas queimadas a $750{ }^{\circ} \mathrm{C}$. Nota-se que a incorporação das cinzas promoveu diminuição da retração linear para todas as incorporações, havendo a menor retração para a composição com $5 \%$ de resíduo. Este comportamento está relacionado à menor perda ao fogo da cinza de fundo em comparação com a massa argilosa. A presença de carbonatos na cinza contribui para a redução da retração linear da massa argilosa, que pode ser devida ao aprisionamento de gás carbônico no interior da cerâmica durante a queima. A Fig. 4c mostra a tensão de ruptura à flexão das peças cerâmicas queimadas a $750{ }^{\circ} \mathrm{C}$. Observase que a incorporação das cinzas reduziu drasticamente a resistência mecânica das peças, ainda que a porosidade tenha diminuído. Este resultado aparentemente contraditório indica que possivelmente as partículas de cinza atuem como pontos de concentração de tensão, causando assim, diminuição da resistência mecânica.

A Fig. 5 apresenta as micrografias por microscopia
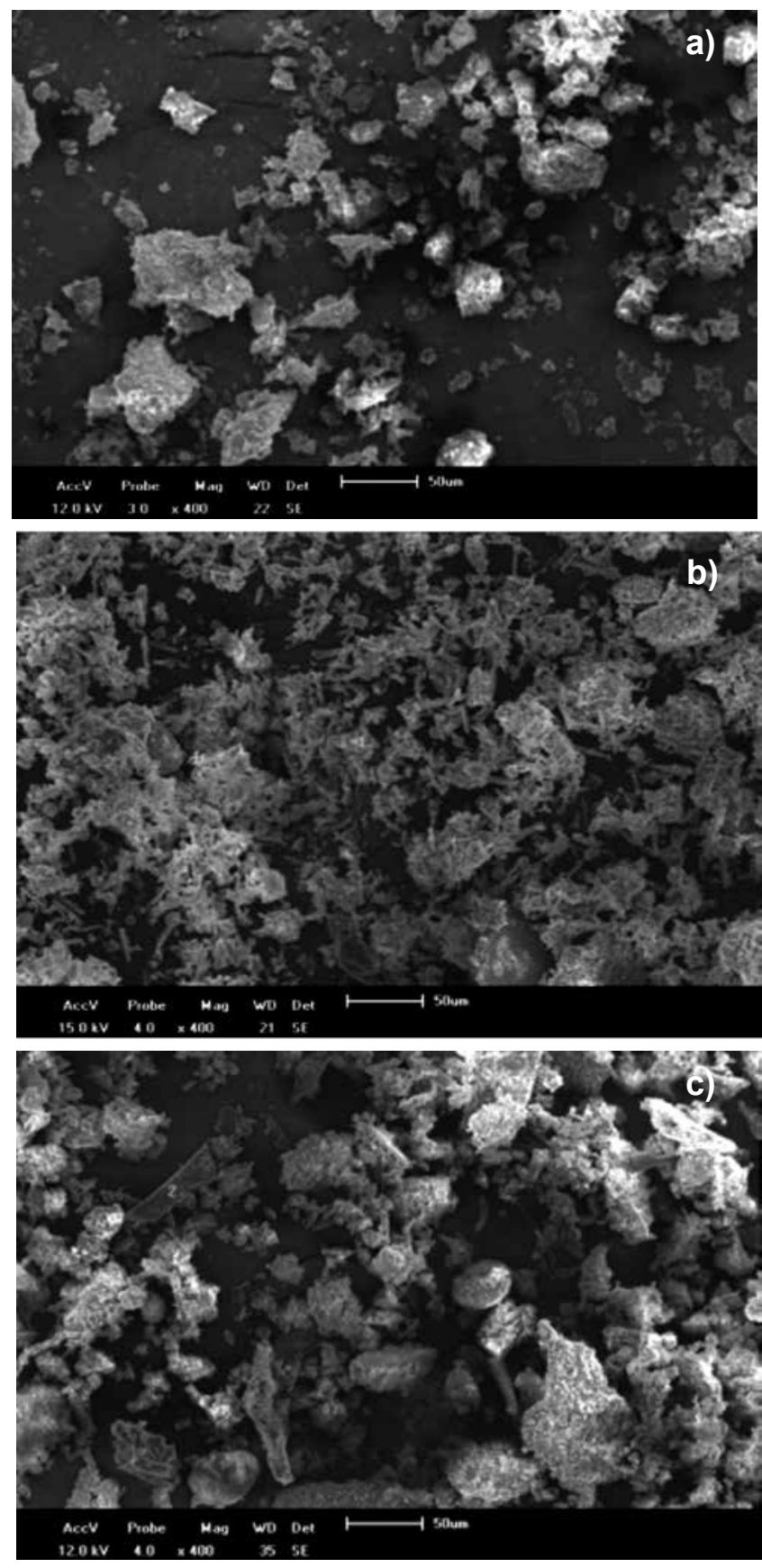

Figura 3: Micrografias obtidas por microscopia eletrônica de varredura da massa cerâmica (a), cinza volante (b) e cinza de fundo (c).

[Figure 3: SEM micrographs of clayey mass (a), fly ash (b), and bottom ash (c).]

óptica das superfícies das peças queimadas. A análise microestrutural dos corpos cerâmicos queimados contribui para o maior entendimento do comportamento das suas propriedades em função da adição das cinzas. $\mathrm{Na} \mathrm{MO}$ das peças sem adição de cinzas é possível notar regiões com diferentes colorações. As partículas mais avermelhadas formam-se pela desidratação de hidróxidos de ferro, como da goetita, presentes nas argilas de Campos dos Goytacazes [7]. Podem ser observadas partículas inertes de quartzo, 

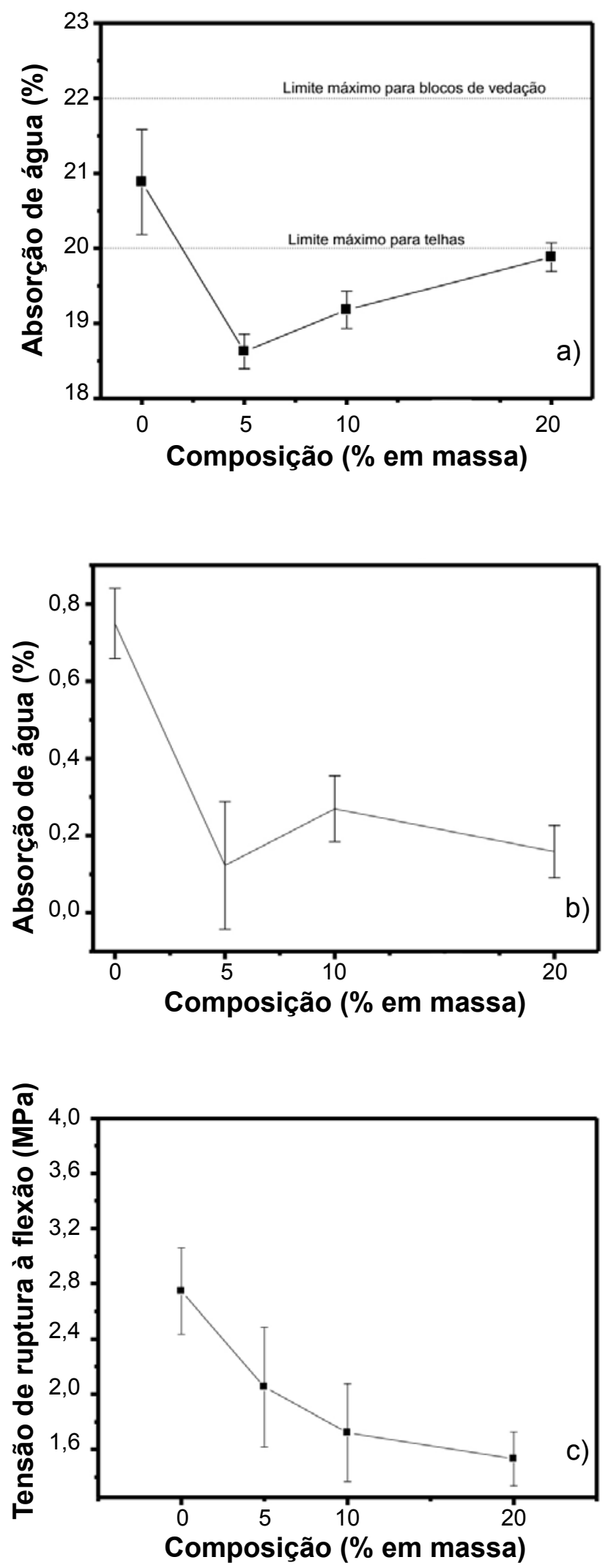

Figura 4: Absorção de água (a), retração linear (b) e tensão de ruptura à flexão (c) das peças queimadas a $750^{\circ} \mathrm{C}$.

[Figure 4: Water absorption (a), linear shrinkage (b), and flexural rupture strength of the ceramic bodies fired at $750^{\circ} \mathrm{C}$.]

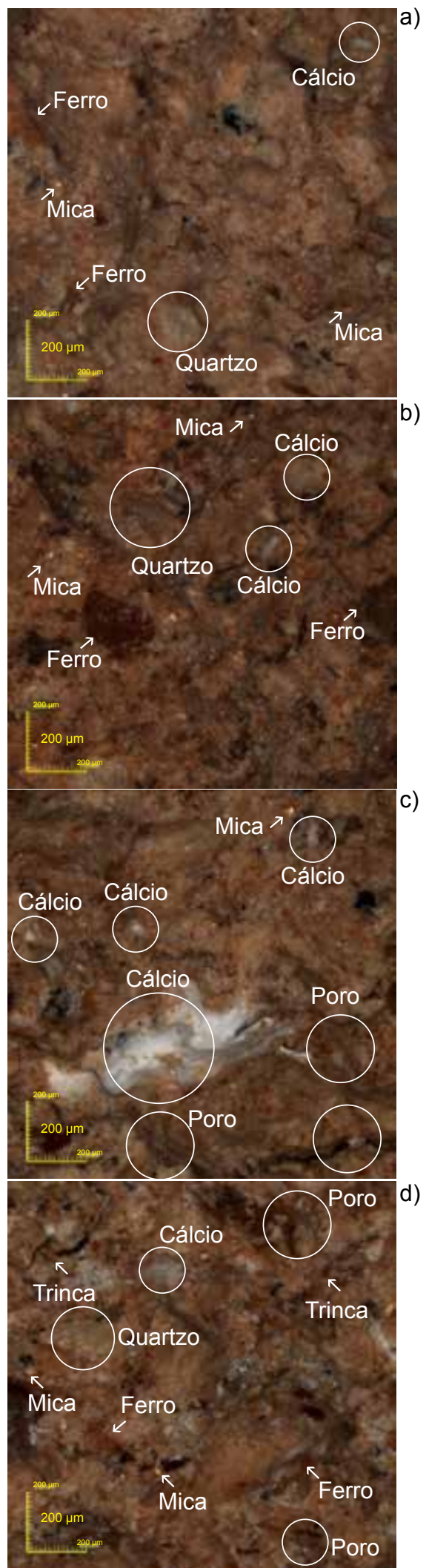

Figura 5: Micrografias ópticas das cerâmicas queimadas a $750{ }^{\circ} \mathrm{C}$ : a) sem adição de cinzas; b) com $5 \%$ de cinzas; c) com $10 \%$ de cinzas; d) com $20 \%$ de cinzas.

[Figure 5: Optical microscopy micrographs of the ceramic fired at $7500^{\circ} \mathrm{C}$ : a) without ashes; b) with $5 \mathrm{wt} \%$ ashes; c) with $10 \mathrm{wt} \%$ ashes; d) with $20 \mathrm{wt} \%$ ashes.] 

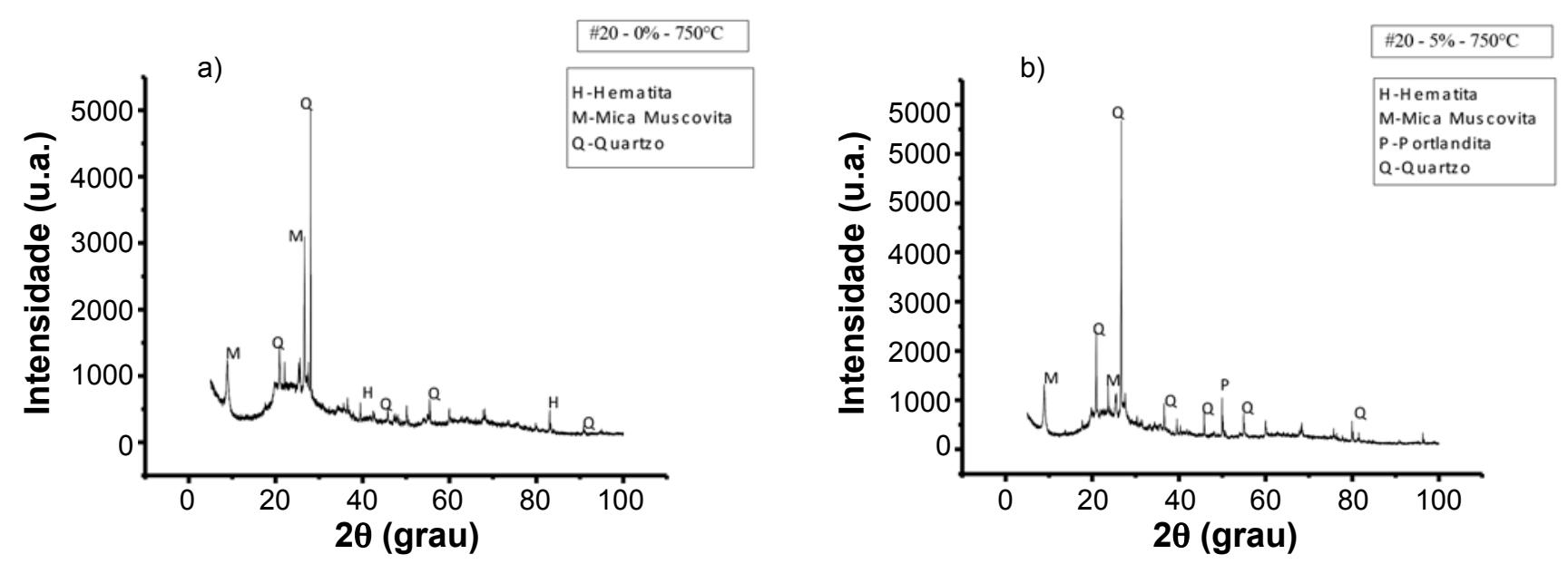

Figura 6: Difratogramas de raios $\mathrm{X}$ das cerâmicas queimadas a $750{ }^{\circ} \mathrm{C}$ : a) sem adição de cinzas; b) com $5 \%$ de cinzas na composição.

[Figure 6: X-ray diffraction patterns of the ceramic bodies fired at $750^{\circ} \mathrm{C}:$ a) without ashes; b) with $5 \mathrm{wt} \%$ ashes.]

que podem atuar como pontos de tensão ocasionando o aparecimento de trincas, o que não ocorreu com as peças sem adição de cinzas. Há ainda mineral micáceo. Com a incorporação das cinzas as fases contendo cálcio ficam evidentes devido à presença de compostos de cálcio nas cinzas volantes, como indicado no difratograma de raios X. Com a incorporação de $10 \%$ de cinzas começam a aparecer poros nas peças, o que concorda com o resultado do teste de absorção de água. Incorporando-se $20 \%$ de cinzas, ocorrem poros e ainda trincas. É possível notar que quanto maior a incorporação das cinzas, mais irregulares ficaram as superfícies das peças cerâmicas, aumentando a porosidade, causando maior absorção de água e menor resistência mecânica, como visto anteriormente.

A Fig. 6 mostra os picos de difração de raios $\mathrm{X}$ das amostras queimadas sem resíduo e com $5 \%$ de cinzas. Os picos de difração são parecidos porque a quantidade de cinzas não foi suficiente para destacar a diferença relativa à incorporação do resíduo na massa cerâmica. Observam-se fases cristalinas como hematita, mica muscovita e quartzo. Os minerais mica e quartzo originam-se da argila natural. A hematita tem origem na decomposição da goetita, que ocorre entre 200 e $400{ }^{\circ} \mathrm{C}$, e ainda nas cinzas de fundo. A portlandita tem origem nas cinzas de fundo, como indicado no difratograma de raios $\mathrm{X}$ das matérias-primas.

\section{CONCLUSÕES}

Neste trabalho de caracterização e incorporação de até $20 \%$ em massa de cinza de resíduo sólido urbano em cerâmica vermelha, para queima a $750{ }^{\circ} \mathrm{C}$, pode-se concluir que: os principais componentes químicos das matériasprimas são sílica $\left(\mathrm{SiO}_{2}\right)$, alumina $\left(\mathrm{Al}_{2} \mathrm{O}_{3}\right)$ e óxido de cálcio $(\mathrm{CaO})$. A incorporação de cinza reduziu a absorção de água da cerâmica em todas as quantidades incorporadas. A retração linear da cerâmica foi reduzida em todas as quantidades incorporadas. A resistência mecânica da massa argilosa sofreu brusca redução com incorporação de $20 \%$ de cinza, sendo a incorporação de $5 \%$ a que menos reduziu esta propriedade. A cinza do RSU apresenta partículas que se encontram quase que na totalidade maiores que 20 $\mu \mathrm{m}$, o que a torna desplastificante. Os resultados indicam que a incorporação deste tipo de cinza em cerâmica vermelha é promissora, podendo assim se tornar um destino ambientalmente correto para este resíduo. Este estudo mostra resultados que sugerem a incorporação de quantidades em torno de $5 \%$ em massa de cinzas na argila para não prejudicar o comportamento mecânico da cerâmica, bem como evitar o aparecimento de porosidade aberta excessiva.

\section{AGRADECIMENTOS}

Os autores agradecem a Usinaverde S/Apelo fornecimento das cinzas utilizadas nesta pesquisa, ao $\mathrm{CNPq}$ (Proc. 302930/2014-0) e à FAPERJ (Proc. E-26/201.192/2014), pelo financiamento desta pesquisa.

\section{REFERÊNCIAS}

[1] V.M. Tallini Jr., V. Mymrine, R.A.C. Ribeiro, H.A. Ponte, "Reciclagem de Resíduos Industriais em Materiais Cerâmicos", Anais $51^{\circ}$ Congresso Brasileiro de Cerâmica, Salvador, BA, Anais eletrônicos, CD-ROM (2007).

[2] M. Ahmaruzzaman, Prog. Energy Combust. Sci. 36 (2010) 327-363.

[3] B. Scheetz, E. Russell, Curr. Opin. Solid State Mater. Sci. 3 (1998) 510-520.

[4] FUNASA/MS. Manual de Saneamento. Fundação Nacional da Saúde, Ministério da Saúde, Departamento de Saneamento, Brasília (2007) 266.

[5] Usina Verde. Disponível em <http://www.usinaverde. com.br $>$ Acesso em 1 set (2014).

[6] H.H. Murray, Applied Clay Mineralogy - Occurrences, Processing and Application of Kaolins, Bentonites, 
Palygorskite-sepiolite, and Common Clays, $1^{\mathrm{a}}$ Ed., Elsevier, Amsterdan, Holanda (2007) 142-144.

[7] C.M.F. Vieira, R.M. Pinheiro, Cerâmica 57 (2011) 319323.

[8] C.R. Cheeseman, C. Sollars, S. McEntee, Resources, Conservation Recycling 40 (2003) 13-25.

[9] Z. Haiying, Z. Youcai, Q. Jingyu, J. Hazard. Mater. 141 (2007) 106-114.

[10] J. Jian-Guo, X. Xin, W. Jun, Y. Shi-Jian, Z. Yan, J. Environ. Sci. 19 (2007) 458-463.

[11] E. Rambaldi, L. Esposito, F. Andreola, L. Barbieri, I.
Lancellotti, I. Vassura, Ceram. Int. 36 (2010) 2469-2476.

[12] Z. Haiying, Z. Youcai, Q. Jingyu, Waste Manage. 31 (2011) 331-341.

[13] ABNT - Associação Brasileira de Normas Técnicas, NBR 15270-1:2005, "Blocos cerâmicos para alvenaria de vedação - Terminologia e requisitos", Rio de Janeiro (2005). [14] ABNT - Associação Brasileira de Normas Técnicas. NBR 15310:2005/Em.1:2009, "Componentes cerâmicos Telhas - Terminologia, requisitos e métodos de ensaios", Rio de Janeiro (2009).

(Rec. 01/10/2015, Rev. 04/01/2016, Ac. 07/03/2016) 